\title{
Repatriation rates in Filipino seafarers: a five-year study of 6,759 cases
}

\author{
Antonio Roberto M. Abaya ${ }^{1}$, Saren Roldan ${ }^{1}$, Jose Carlo E. Ongchangco ${ }^{1}$, \\ Regina M. Ronquillo-Sarmiento ${ }^{1}$, Raymond Francis R. Sarmiento ${ }^{2}$ \\ ${ }^{1}$ Health Metrics, Inc., Makati City, Philippines \\ ${ }^{2}$ Health Futures Foundation, Inc., Quezon City, Philippines
}

\begin{abstract}
Background: Studies on medical repatriation of seafarers due to illnesses and injuries have been limited. The aim of the study was to describe the epidemiology of medical repatriation among Filipino seafarers. Materials and methods: We performed a retrospective analysis of records from January 2010 to December 2014 of medical repatriations of Filipino seafarers from the claims and legal departments of different manning agencies in Manila, Philippines.

Results: We analysed data from a total of 6,759 medical repatriation cases in a 5-year period, representing 174 shipping companies and 2,256 vessels. The total number of seafarers deployed from the manning agencies where we obtained data was 388,963 with the rate of medical repatriations calculated at $1.7 \%$. We used the $10^{\text {th }}$ revision of the International Statistical Classification of Diseases and Related Health Problems (ICD-10) to determine the most common causes of repatriation. We found that these were injuries (trauma), musculoskeletal disorders, gastrointestinal problems, and genitourinary illnesses. We also conducted an analysis of the most common clinical problems per organ system.

Conclusions: Filipinos represent the most numerous group of seafarers in the world. Profiling their health issues may help in optimising current protocols, implementing health surveillance programs, and formulating health policies for seafaring personnel. In addition, our study results may help physicians performing pre-employment medical examinations to identify and manage conditions that are at a high risk of medical repatriation.
\end{abstract}

(Int Marit Health 2015; 66, 4: 189-195)

Key words: occupational health, medical repatriation, epidemiology, seafarers, occupational injury

\section{INTRODUCTION}

Studies on medical repatriation of seafarers due to illnesses and injuries have been limited [1,2]. An extensive review of the literature shows only small groups of nationalities have been studied [3, 4]. In the 2009 study by Bell et al. [5], they showed a distribution of crew illnesses per nationality on board a passenger ship.

Filipinos represent the most numerous group of seafarers in the world and they represent approximately 25-30\% [6] of the whole seafaring population. Statistics from the Philippine Overseas Employment Administration (POEA) showed that there were 401,826 deployments of Filipino seafarers in 2014 alone [7]. Profiling their health issues would help the government and relevant agencies in formulating occupational health policies and protocols that could help lessen the incidence of injuries and illnesses causing medical repatriations. In addition, ensuring the health and safety of these marine professionals would be in the best interest of protection and indemnity insurance firms since they are ultimately responsible for the medical care coverage of injured or ill seafarers.

As an initial step to addressing the dearth of information relating to medical repatriations from the largest seafaring group in the world, this study describes the epidemiology of medical repatriation among seafarers in the Philippines. We also aimed to describe the most common causes of medical 
repatriations and the most common disorders or diseases per organ system. Based on these findings, implementing screening protocols from pre-employment clinics and occupational health interventions must be strongly considered in order to reduce the burden of medical repatriations on Filipino seafarers.

\section{MATERIALS AND METHODS}

Seafarers undergo several procedures upon medical repatriation back to the Philippines. The seafarer is required by law to report to the hiring manning agency within $72 \mathrm{~h}$ from arrival. He or she is instructed to go to the designated clinician, hospital, or clinic where the management of his illness will be assessed and treated. In cases where hospitalisation is immediately required, an ambulance will already be present at the airport for immediate transit to a medical centre. Generally, the medical personnel handling the case updates the manning agencies with medical reports on the diagnosis and status of the patient. The manning agency reports back to the ship owner or principal for approval on medical costs, sick wages, disability claims, and other costs.

Based on knowledge on the intricacies of medical repatriation in the Philippines, we collected aggregate data for the period of January 2010 to December 2014 from the claims and legal departments manning agencies to get the most accurate and complete data on medical repatriation cases. In this study, we used and analysed de-identified, non-coded data. We collected data on the age of the crew, position, type of vessel, date of embarkation, date of repatriation, diagnosis, return to work status, and the total number of seafaring deployments of the manning agencies from July 2009 to June 2014. We did not collect or use any personally identifiable information and we did not have any interaction with any of the individual crew. We used the $10^{\text {th }}$ revision of the International Statistical Classification of Diseases and Related Health Problems (ICD-10) [8] to determine the most common causes of repatriation. We performed data management and descriptive analyses using Microsoft Excel 2013.

\section{RESULTS}

A total of 6,759 medically repatriated cases were reported for the period of January 2010 to December 2014 spanning 2,256 vessels and representing 174 different shipping companies from 12 manning agencies which cooperated with the investigators. Also, there were 338,963 deployments from the same manning agents for the period of July 2009 to June 2014. Since the average deployment period of the seafarer was 6 months, we assumed that the earliest deployment for the start of the repatriation study would be at least 6 months before; hence, we started counting the number of deployments from July 2009 . We also ended the
Table 1. Distribution of deployments and repatriation cases among Filipino seafarers

\begin{tabular}{lll}
\hline Period & $\begin{array}{l}\text { Number of } \\
\text { deployments }\end{array}$ & $\begin{array}{l}\text { Number of } \\
\text { repatriation } \\
\text { cases (\%) }\end{array}$ \\
\hline July 2009 - June 2010 & 68,678 & $1,320(1.9 \%)$ \\
July 2010 - June 2011 & 73,953 & $1,245(1.7 \%)$ \\
July 2011 - June 2012 & 82,697 & $1,323(1.6 \%)$ \\
July 2012 - June 2013 & 78,986 & $1,375(1.7 \%)$ \\
July 2013 - June 2014 & 84,649 & $1,496(1.8 \%)$ \\
Total & 388,963 & $6,759(1.7 \%)$ \\
\hline
\end{tabular}

deployment numbers 6 months before the closure of the repatriation case study (June 2014). We considered this as the true repatriation rate because the seafarers would have been more likely to be deployed prior to the study period, which was January 2010 - December 2014 (Table 1). We divided the number of repatriations from January 2010 to December 2014 by the number of deployment cases from July 2009 to June 2014 to arrive at a true repatriation rate of $1.7 \%$ for the 5 -year period.

Table 2 shows the distribution of the causes of medical repatriation using ICD-10 classifications. We separated the trauma cases (fractures, lacerations, burns, etc.), which accounted for $21.4 \%$ of medical repatriations, from the musculoskeletal disorders (19.4\%). The third most common cause of repatriations were gastrointestinal problems (17.3\%), which included all digestive tract problems, from swallowing disorders to anorectal diseases. We also included umbilical and inguinal hernias in this group. Genitourinary system problems accounted for $8.9 \%$ of all cases and included all kidney, bladder, and prostate diseases. Cardiovascular system problems accounted for $8.1 \%$ of all cases and included hypertension (uncontrolled), heart disease, cerebrovascular disease and venous diseases. Dermatological problems (5.6\%), infectious diseases (3.6\%), respiratory disorders (3.0\%), ophthalmological problems (2.9\%), and neoplastic diseases (2.1\%) rounded out the top 10.

We also conducted an analysis of the main causes of medical repatriation per organ system involvement. Figure 1 shows the distribution of injured body parts in seafarers due to trauma or accidents. The hand (549 cases) was the most commonly injured body part followed by the upper extremity (171 cases) defined as from the shoulder to forearm. The ankle and foot had 159 cases, while there were 148 knee injuries. Injuries to the torso (chest to pelvis) totalled 128 cases. There were 82 cases of burns, 81 head injuries, 69 lower limb injuries, and 63 injuries involving the eye.

Table 3 shows the distribution of injuries or illnesses per organ system. We found 555 cases of lower back pain and 
Table 2. Distribution of the causes of medical repatriation using ICD-10

\begin{tabular}{|c|c|c|c|}
\hline $\begin{array}{l}\text { Causes of medical } \\
\text { repatriation }\end{array}$ & $\begin{array}{l}\text { ICD-10 } \\
\text { code range }\end{array}$ & $\begin{array}{l}\text { ICD-10 } \\
\text { code category }\end{array}$ & $\begin{array}{l}\text { Number of medical } \\
\text { repatriations (\%) }\end{array}$ \\
\hline Injury (trauma) & S00-T98 & Injury, poisoning and certain other consequences of external causes & $1,450(21.4 \%)$ \\
\hline Musculoskeletal & M00-M99 & Diseases of the musculoskeletal system and connective tissue & $1,294(19.1 \%)$ \\
\hline Gastrointestinal & K09-K93 & Diseases of the digestive system & $1,155(17.1 \%)$ \\
\hline Genitourinary & N00-N99 & Diseases of the genitourinary system & $602(8.9 \%)$ \\
\hline Cardiovascular & $100-199$ & Diseases of the circulatory system & $549(8.1 \%)$ \\
\hline Dermatological & L00-L99 & Diseases of the skin and subcutaneous tissue & $376(5.6 \%)$ \\
\hline Infectious & A00-B99 & Certain infectious and parasitic diseases & $242(3.6 \%)$ \\
\hline Respiratory & J00-J99 & Diseases of the respiratory system & $206(3.0 \%)$ \\
\hline Ophthalmological & $\mathrm{H} 00-\mathrm{H} 59$ & Diseases of the eye and adnexa & $193(2.9 \%)$ \\
\hline Neoplastic & COO-D48 & Neoplasms & $144(2.1 \%)$ \\
\hline Psychiatric or psychological & F00-F99 & Mental and behavioural disorders & $118(1.8 \%)$ \\
\hline Endocrinological & E00-E90 & Endocrine, nutritional and metabolic diseases & $109(1.6 \%)$ \\
\hline Neurological & G00-G99 & Diseases of the nervous system & $88(1.3 \%)$ \\
\hline Otological & H60-H95 & Diseases of the ear and mastoid process & $85(1.3 \%)$ \\
\hline Others & Not available & Not available & $47(0.7 \%)$ \\
\hline Dental & K00-K08 & Diseases of oral cavity, salivary glands and jaws & $38(0.6 \%)$ \\
\hline Obstetrical & 000-099 & Pregnancy, childbirth and the puerperium & $31(0.5 \%)$ \\
\hline Death & 146 & Cardiac arrest & $20(0.3 \%)$ \\
\hline Haematological & D50-D89 & $\begin{array}{l}\text { Diseases of the blood and blood-forming organs and } \\
\text { certain disorders involving the immune mechanism }\end{array}$ & $12(0.2 \%)$ \\
\hline
\end{tabular}

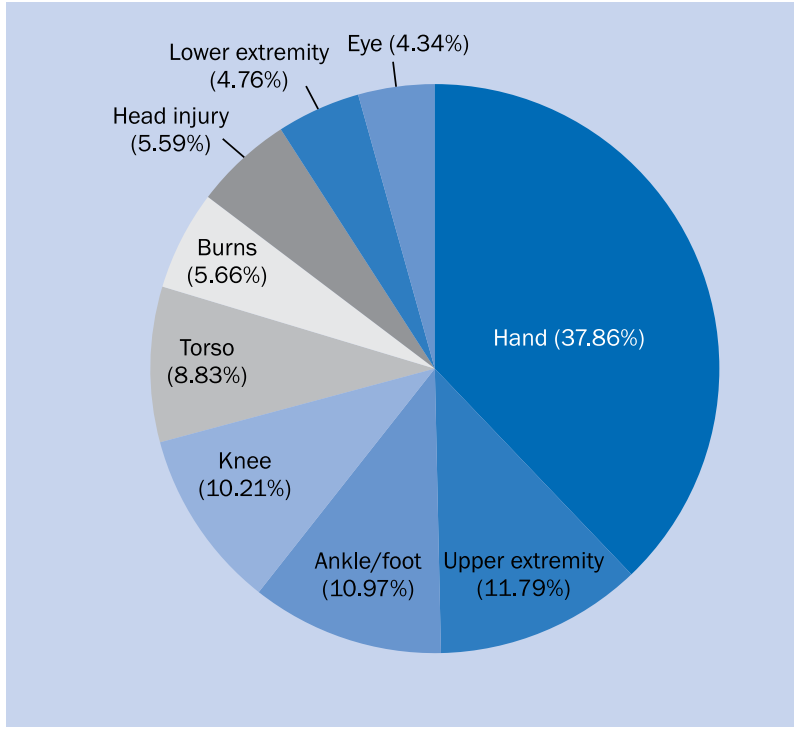

Figure 1. Distribution of injured body parts in seafarers due to trauma or accidents $(n=1,450)$

185 cases of musculoskeletal strain in the lower extremity, including the knee. The hand was involved in 147 cases. Unspecified arthritis including gout was reported in 131 cases.
The shoulder and the arm were affected in 116 cases. There were 94 cases involving the ankle and foot were reported and 66 cases where the cervical spine was affected.

Gastrointestinal system problems accounted for $17.3 \%$ of all medical repatriations and these were broken down as follows: 235 cases of diagnosed appendicitis; 174 cases of acid peptic disease, including duodenal ulcers, gastroesophageal reflux disease, and gastritis were responsible for. Hernias, including inguinal and umbilical hernias, were reported in 161 cases. The data we received reported "abdominal pain (or similar)" in 149 cases. This is not a clinical diagnosis; however it was still used as a cause for repatriation. There were 130 gall bladder diseases including acute cholecystitis, polyps, cholangitis, and gall bladder stones. External and internal haemorrhoids accounted for 128 cases of repatriation. There were 76 cases of small intestine and colon problems including obstruction, diverticulitis, etc. Anal problems, including fistulas, accounted for 61 cases. There were 27 cases of gastroenteritis and 14 cases of liver pathology (fatty liver, cirrhosis).

Genitourinary problems accounted for $8.9 \%$ of all repatriation cases. There were a total of 264 repatriations due to kidney stones. Testicular diseases such as varicocoele and epididymitis accounted for 150 cases. There were 
Table 3. Distribution of injuries or illnesses by organ system

\begin{tabular}{|c|c|}
\hline $\begin{array}{l}\text { Organ system and chief complaint } \\
\text { or injured body part }\end{array}$ & $\begin{array}{l}\text { Rate of medical } \\
\text { repatriation (\%) }\end{array}$ \\
\hline \multicolumn{2}{|l|}{ Musculoskeletal $(n=1,294)$} \\
\hline Low back pain & $42.9 \%$ \\
\hline Leg/knee & $14.3 \%$ \\
\hline Hand & $11.4 \%$ \\
\hline Unspecified arthritis & $10.1 \%$ \\
\hline Shoulder & $9.0 \%$ \\
\hline Ankle/foot & $7.3 \%$ \\
\hline Cervical spine & $5.1 \%$ \\
\hline \multicolumn{2}{|l|}{ Gastrointestinal $(n=1,155)$} \\
\hline Appendicitis & $20.3 \%$ \\
\hline Acid peptic disease & $15.1 \%$ \\
\hline Hernia & $13.9 \%$ \\
\hline Abdominal pain & $12.9 \%$ \\
\hline Gall bladder & $11.3 \%$ \\
\hline Haemorrhoids & $11.1 \%$ \\
\hline Intestinal & $6.6 \%$ \\
\hline Anal problems & $5.3 \%$ \\
\hline Acute gastroenteritis & $2.3 \%$ \\
\hline Liver & $1.2 \%$ \\
\hline \multicolumn{2}{|l|}{ Genitourinary $(n=602)$} \\
\hline Kidney stones & $43.8 \%$ \\
\hline Testicular disease & $24.9 \%$ \\
\hline Genitourinary infection & $13.1 \%$ \\
\hline Prostate & $10.0 \%$ \\
\hline Gynaecological & $4.2 \%$ \\
\hline Kidney & $4.0 \%$ \\
\hline \multicolumn{2}{|l|}{ Cardiovascular $(n=549)$} \\
\hline Hypertension & $34.2 \%$ \\
\hline Coronary artery disease & $31.2 \%$ \\
\hline Cerebrovascular disease & $13.5 \%$ \\
\hline Varicose & $11.3 \%$ \\
\hline Congestive heart failure & $4.4 \%$ \\
\hline Arrhythmia & $3.6 \%$ \\
\hline Vascular & $1.8 \%$ \\
\hline \multicolumn{2}{|l|}{ Dermatological $(n=376)$} \\
\hline Dermatitis & $37.0 \%$ \\
\hline Abscess & $29.0 \%$ \\
\hline Cellulitis & $13.3 \%$ \\
\hline Cysts & $8.0 \%$ \\
\hline Urticaria & $6.4 \%$ \\
\hline Psoriasis & $3.5 \%$ \\
\hline Warts & $2.9 \%$ \\
\hline
\end{tabular}

Table 3. cont. Distribution of injuries or illnesses by organ system

\begin{tabular}{|c|c|}
\hline $\begin{array}{l}\text { Organ system and chief complaint } \\
\text { or injured body part }\end{array}$ & $\begin{array}{l}\text { Rate of medical } \\
\text { repatriation (\%) }\end{array}$ \\
\hline \multicolumn{2}{|l|}{ Respiratory $(n=206)$} \\
\hline Respiratory infection & $66.5 \%$ \\
\hline $\begin{array}{l}\text { Asthma, chronic obstructive } \\
\text { pulmonary disease }\end{array}$ & $17.5 \%$ \\
\hline Polyps & $4.4 \%$ \\
\hline Pleural effusion & $4.4 \%$ \\
\hline Pharynx/upper airway & $3.4 \%$ \\
\hline Epistaxis & $2.9 \%$ \\
\hline Pneumothorax & $1.0 \%$ \\
\hline \multicolumn{2}{|l|}{ Ophthalmological $(n=193)$} \\
\hline Infection/inflammation & $34.7 \%$ \\
\hline Visual defects & $19.7 \%$ \\
\hline Retinopathy & $15.0 \%$ \\
\hline Pterygium & $10.9 \%$ \\
\hline Cataract & $9.8 \%$ \\
\hline Optic nerve & $4.2 \%$ \\
\hline Haemorrhage & $2.6 \%$ \\
\hline Cornea & $2.1 \%$ \\
\hline Glaucoma & $1.0 \%$ \\
\hline \multicolumn{2}{|l|}{ Psychiatric/psychological $(n=118)$} \\
\hline Anxiety/adjustment disorder & $49.2 \%$ \\
\hline Depression & $28.0 \%$ \\
\hline Psychosis/schizophrenia & $17.0 \%$ \\
\hline Bipolar disorder & $5.9 \%$ \\
\hline \multicolumn{2}{|l|}{ Endocrine $(n=109)$} \\
\hline Diabetes & $57.8 \%$ \\
\hline Thyroid & $43.8 \%$ \\
\hline \multicolumn{2}{|l|}{ Neurological $(n=88)$} \\
\hline Neuropathy & $28.4 \%$ \\
\hline Bell's palsy & $22.7 \%$ \\
\hline Migraine & $20.5 \%$ \\
\hline Seizures/epilepsy & $14.8 \%$ \\
\hline Others & $13.6 \%$ \\
\hline \multicolumn{2}{|l|}{ Otological $(n=85)$} \\
\hline Ear infection & $38.8 \%$ \\
\hline Hearing loss & $25.9 \%$ \\
\hline Vertigo & $25.9 \%$ \\
\hline Perforation & $5.9 \%$ \\
\hline Ear pain & $2.4 \%$ \\
\hline Cyst & $1.2 \%$ \\
\hline
\end{tabular}


Table 3. cont. Distribution of injuries or illnesses by organ system

\begin{tabular}{ll}
\hline $\begin{array}{l}\text { Organ system and chief complaint } \\
\text { or injured body part }\end{array}$ & $\begin{array}{l}\text { Rate of medical } \\
\text { repatriation (\%) }\end{array}$ \\
\hline Infectious diseases $(\mathbf{n}=\mathbf{2 4 2})$ & $36.8 \%$ \\
Viral exanthems & $20.7 \%$ \\
Tuberculosis & $13.2 \%$ \\
Sepsis & $12.8 \%$ \\
Malaria & $7.9 \%$ \\
Hepatitis & $4.1 \%$ \\
Typhoid/enteritis & $2.1 \%$ \\
Meningitis & $1.7 \%$ \\
Syphilis, gonorrhoea & $0.8 \%$ \\
Rheumatic fever & \\
Neoplastic ( $\mathrm{n}=144)$ & $33.3 \%$ \\
Head or neck & $21.8 \%$ \\
Gastrointestinal & $13.6 \%$ \\
Female reproductive system, & \\
including breast & $11.4 \%$ \\
Skin & $8.3 \%$ \\
Bone/extremity & $6.1 \%$ \\
Haematology & $5.3 \%$ \\
Genitourinary & $4.6 \%$ \\
Lung & $4.6 \%$ \\
Unknown &
\end{tabular}

79 infections of the kidney and/or urinary tract. There were 60 cases of prostate disease. There were 25 gynaecologic cases such as metrorrhagia and ovarian cysts. There were 14 cases of kidney disease, including renal failure and renal cysts.

Cardiovascular diseases accounted for $8.1 \%$ of all repatriation cases. The top cause of cardiovascular disease was hypertension with 188 cases of repatriation. This was followed by coronary artery disease with 171 cases. There were 74 cases of cerebrovascular disease. A total of 62 cases of varicose veins were reported. There were 24 cases of congestive heart failure from various causes. Arrhythmias accounted for 20 cases and there were 10 vascular cases reported.

Dermatological diseases caused $5.6 \%$ of all repatriations. There were 139 cases of dermatitis, followed by 109 cases of abscesses and 50 cases of cellulitis. There were 24 cases of superficial skin cysts and 20 cases of urticaria. There were 13 psoriasis cases 11 cases of skin warts.

Respiratory diseases caused 3.1\% of all repatriations. There were a total of 137 infections and 36 cases of acute and chronic obstructive pulmonary disease. There were 9 cases of nasal polyps and 9 cases of pleural effusion. The upper airway pharynx was affected in 7 cases. Epistaxis of unknown origin in 6 cases and 2 pneumothorax cases were reported.
Ophthalmological diseases caused $2.9 \%$ of all repatriation cases. Infections and inflammations were the top cause with 67 cases. This was followed by visual defects/errors of refraction with 38 cases. There were 29 cases of various retinopathies. There were 29 pterygium cases and 21 cataract cases. Optic nerve damage was reported in 8 cases and there were 5 cases of haemorrhage. Corneal disease was present in 4 cases and glaucoma reported in 2 cases.

We found that $1.8 \%$ of all medical repatriations were caused by psychiatric or psychological disorders. The most common cause was anxiety and/or adjustment disorders at 58 cases. There were 33 cases of depression, 20 cases of schizophrenia/psychosis, and 7 cases of bipolar disorders.

Endocrine diseases comprised $1.6 \%$ of all repatriation cases reported. There were 63 cases of diabetes and diabetes related cases and 46 cases of thyroid disorders.

Neurological disorders accounted for $1.3 \%$ of the repatriations. Various neuropathies were seen in 25 cases. There were 20 cases of Bell's palsy. Severe migraine was the cause of repatriation in 18 cases. There were 13 cases of seizures and epilepsy. Other neurological disorders, such as Guillain-Barre and vasovagal syndromes, were reported in 12 cases.

Otological problems were reported in $1.3 \%$ of all repatriations. There were a total of 33 external and middle ear infections reported. Hearing loss was reported in 22 cases. There were also 22 cases of vertigo. There were 5 cases of tympanic membrane perforation, ear pain in 2 cases and an ear cyst in 1 case.

We also included two additional categories in Table 3 that we used as part of the organ system classification of injuries or illnesses: infectious diseases and neoplastic diseases. Infectious diseases accounted for $3.6 \%$ of all repatriations. There were a total of 89 viral exanthems that caused repatriations. This was followed by 50 cases of tuberculosis mainly pulmonary. There were 32 cases of sepsis and 31 cases of malaria repatriated. There were 19 cases of hepatitis and 10 cases of typhoid fever. There were 5 cases of meningitis and 4 cases of syphilis/gonorrhoea. Only 2 cases of rheumatic fever were reported.

Neoplastic diseases made up $2.1 \%$ of all repatriated cases. The most common cancers were those in the head and neck area with 44 cases, followed by the gastrointestinal cancers with 29 . There were 18 female reproductive cancers while there were 15 skin disorders comprised mostly of benign lipomas. There were 11 bone cancers on the extremities and 8 leukaemia cases. There were 7 genitourinary and 6 lung cancer cases reported. A total of 6 cancers were of unknown origin.

Lastly, the remaining cases were classified as dental problems $(n=38)$, majority of which were tooth aches and dental abscesses. Most obstetrics cases $(n=31)$ were pregnancy-related. For haematology cases $(n=12)$, the main 
cause of repatriation was anaemia. There were 20 deaths reported and we classified 47 cases as "other" because no clear diagnosis or classification was indicated.

\section{DISCUSSION}

To our knowledge, this is the first report describing the causes of medical repatriations among seafarers from the Philippines using data from the largest dataset on medical repatriations in the world at present. We did not find any other study similar to ours that has looked into the epidemiology of seafarer medical repatriations of a single nationality.

Based on POEA data for the period of July 2009 to June 2014 , the total number of deployments in the country was $1,852,111$ [6]. This means that in this study, we collected and analysed data on $21.0 \%$ of the total number of deployments in the Philippines for the same period.

A number of studies have tried to discuss the cause of repatriation in various nationalities, with a majority of them looking at accidents and trauma aboard ships [9-13]. Several studies have looked at the causes of mortality on board ships [14-16]. In 2004, Cruz [17] reported that low back pain was the largest cause of injuries among Filipino seamen. The importance of looking at all the medical causes of repatriation could help formulate policies for health regulations with regards medical screening and decision-making for clinicians. Because of the relatively higher accident rate on board, Jensen et al. [12] have recommended more injury prevention measures. Several studies have also investigated on illnesses that cause medical repatriations and reported that cardiovascular problems remain predominant among seafarers [18-21].

In this study, the top 5 causes of medical repatriation as reported were injuries (21.4\%), musculoskeletal (19.4\%), gastrointestinal (17.1\%), genitourinary $(8.9 \%)$ and cardiovascular (8.1\%), which account for nearly $75 \%$ of all repatriations. The most common reason for repatriation is injuries accounting for more than a $5^{\text {th }}$ of all repatriated cases. The results of our study are consistent with those presented by Jensen et al. [22] in 2005 where they looked at 6,461 participants and found that the rate of injury was $9.1 \%$, with blows or knocks and wounds comprising $49 \%$, followed by fractures at $12.4 \%$. They also found that $70 \%$ of injuries occurred on the deck or in engine rooms. In our study, we found that hand trauma causes $40 \%$ of injuries resulting in repatriation, which is generally expected since most seafarers perform some form of manual labour.

Furthermore, we found that musculoskeletal problems, when combined with traumatic injuries, comprise almost $41 \%$ of all repatriations as they are frequently work-related. Of these, we found lower back disorders to be the most common musculoskeletal problem (42.9\%) which was expected because low back pain is one of the most common chief complaints [23], especially among Filipino seafarers
[17]. When both injuries due to trauma and musculoskeletal problems are combined, they account for almost $40 \%$ of all repatriations. This is significant because all these cases could potentially be claimed to be work-related. The high number of work-related injuries underscores the need for adequate training of Filipino seafarers on safety practices on board. Moreover, precautions and safe working conditions must always be instituted in order to reduce and prevent accidents and trauma incidents.

In the 2006 study by Dahl [24], appendicitis was found to be the most common gastrointestinal problem (21\%) among repatriated crew. In this study, the fourth most common cause of gastrointestinal problems reported was abdominal pain, which is not a clear diagnosis; 149 Filipino seafarers were sent home because of abdominal pain. When we reviewed these cases, most patients were cleared by the local physicians in Manila after 1 or 2 days. Many reported to have even felt well upon arrival. We posit that these happened in cases where the captain or port physician could not get a clear diagnosis and for logistic reasons such as port delays, long periods at sea, or other reasons, the authorities decided to repatriate the affected crew members.

In this study, a medical repatriation rate of $1.7 \%$ may be considered a relatively low rate. However, this may mean that Filipino seafarers are a healthy group of seafarers in general. It may also be attributed to the comprehensive health screenings conducted by pre-employment medical clinic personnel in the Philippines.

\section{LIMITATIONS OF THE STUDY}

Several limitations of this study need to be considered. We were only able to gather data from manning agencies located in Manila, Philippines. Therefore, the findings in this study do not represent the population burden of medical repatriations for the entire Philippines. Also, there is likely an underreporting of repatriation cases because it is assumed that Filipino seafarers can be reluctant at times in seeking medical help on board and would prefer to seek treatment after signing off from their country of origin. In addition, since medical repatriation is often due to acute health disorders, latent chronic conditions may have also been underreported. Furthermore, since this is a retrospective analysis and because we analysed aggregate data, the data elements used lack the level of detail and completeness that would have been ideal. Further work is needed to conduct more in-depth analysis of the available data especially given that this is the largest dataset on medical repatriations to date.

\section{CONCLUSIONS}

Medical repatriations impose a major burden on the largest segment of the global seafaring population. The predominance of injuries due to trauma or accidents as well 
as musculoskeletal disorders underscore the need for comprehensive health screenings for Filipino seafarers prior to assuming their jobs on board ships. The results of this study may be used as reference when benchmarking the health of seafarers of any shipping company in the Philippines. Profiling the health issues of Filipino seafarers may help in optimising current protocols, implementing health surveillance programs, and formulating health policies for seafaring personnel. Moreover, our study results may help pre-employment medical exam physicians to identify and manage conditions that are at a high risk for medical repatriation.

\section{REFERENCES}

1. Lefkowitz RY, Slade MD, Redlich CA. Injury, illness, and work restriction in merchant seafarers. Am J Ind Med 2015; 58: 688-696.

2. Lefkowitz, RY, Slade MD, Redlich CA. Risk Factors for Merchant Seafarer Repatriations due to injury or illness at Sea. Int Marit Health 2015; 66: 61-66.

3. Ehara M, Muramatsu S, Sano Y, Takeda S, Hisamune S. The tendency of diseases among seamen during the last fifteen years in Japan. Ind Health 2006; 44: 155-160.

4. Adam B. Association between nationality and occupational injury risk on Danish non-passenger merchant ships. Int Marit Health 2013; 64: 121-125.

5. Bell SSJ, Jensen OC. An analysis of the diagnoses resulting in repatriation of seafarers of different nationalities working on board cruise ships, to inform pre-embarkation medical examination. Medicina Maritima 2009; 9: 32-43.

6. International Labor Organization. Philippines ratification marks global milestone for decent work for seafarers. http://www.ilo.org/ global/standards/maritime-labour-convention/WCMS_187712/ lang-en/index.htm. (Last accessed 28 August 2015).

7. Philippine Overseas Employment Administration. Overseas Employment Statistics 2010-2014. http://www.poea.gov.ph/stats/2014\%20 POEA\%20Stats.pdf. (Last accessed 15 September 2015).

8. World Health Organization. International Statistical Classification of Diseases, 10th revision. http://apps.who.int/classifications/ icd10/browse/2015/en. (Last accessed 20 August 2015).

9. Hisamune S, Amagai K, Kimura N, Kishida K. A study of factors relating to work accidents among seamen. Industrial Health 2006; 44: 144-149.
10. Hansen HL, Laursen LH, Frydberg M, Kristensen S. Major differences in rates of occupational accidents between different nationalities of seafarers. Int Marit Health 2008; 59: 7-18.

11. Tomaszunas $S$, Wecławik $Z$. Accidents and injuries in Polish seafarers. Bull Inst Marit Trop Med Gdynia 1997; 48: 59-73.

12. Jensen OC, Sorensen JF, Kaerlev L, Canals ML, Nikolic N, Saarni H. Self-reported injuries among seafarers. Questionnaire validity and results from an international study. Accid Anal Prev 2004; 36: 405-413.

13. Jensen OC, Sorensen JFL, Canals ML, Hu YP, Nikolic N, Thomas $M$. Incidence of self-reported occupational injuries in seafaring: an international study. Occup Med (Lond) 2004; 54: 548-555.

14. Nielsen D, Hansen HL, Gardner BM, Jungnickel D. Deaths due to disease of seafarers on board Singapore ships. Int Marit Health 2000; 51: 20-29.

15. Weng J, Yang D. Investigation of shipping accident injury severity and mortality. Accid Anal Prev 2015; 76: 92-101.

16. Roberts SE, Nielsen D, Kotłowski A, Jaremin B. Fatal accidents and injuries among merchant seafarers worldwide. Occup Med (Lond) 2014; 64: 259-266.

17. Cruz N. Filipino seamen - major causes of medical repatriation. 01 Aug 2004. Insight 175, 2004, Gard AS, Arendal, Norway.

18. Oldenburg M, Baur X, Schlaich C. Cardiovascular diseases in modern maritime industry. Int Marit Health 2010; 62: 101-106.

19. Rosik E, Jaremin B, Szymańska K. Can general cardiovascular risk evaluation facilitate the assessment for fitness for work and contribute to the reduction of cardiovascular incidents among seaman and fishermen? Int Marit Health 2006; 57: 188-197.

20. Poulsen TR, Burr H, Hansen HL, Jepsen JR. Health of Danish seafarers and fishermen 1970-2010: what have register-based studies found? Scand J Public Health 2014; 42: 534-545.

21. Alves PM, Leigh R, Bartos G, Mody R, Gholson L, Nerwich N. Cardiovascular events on board commercial maritime vessels: a two year review. Int Marit Health 2010; 61: 137-142.

22. Jensen OC, Sorensen JF, Canals ML, Hu Y, Nikolic N, Mozer AA. Non-fatal occupational injuries related to slips, trips and falls in seafaring. Am J Ind Med 2005; 47: 161-171.

23. Fleischer AB Jr, Gardner EF, Feldman SR. Are patients' chief complaints generally specific to one organ system? Am J Manag Care 2001; 7: 299-305.

24. Dahl E. Crew referrals to dentists and medical specialist ashore: a descriptive study of practice on three passenger vessels during one year. Int Marit Health 2006; 57: 127-135. 